\title{
Performance on Water Stability of Cement- Foamed Asphalt Cold Recycled Mixture
}

\author{
Junxiao $\mathrm{Li}^{1 *}$, Wei $\mathrm{Fu}^{2}$, and Hechao Zang ${ }^{1}$ \\ ${ }^{1}$ Shandong Provincial Key Laboratory of Ocean Environmental Monitoring Technology, Institute of \\ Oceanographic Instrumentation, Shandong Academy of Sciences, Qingdao 266001, China \\ ${ }^{2}$ Navy Qingdao First Sanatorium, Qingdao 266001, China
}

\begin{abstract}
Through designing the mixture proportion of foamed asphalt cold in-place recycled mixture combined with the water stability experiment, it shows that the addition of cement can obviously improve foamed asphalt mixture's water stability and the best cement admixture is between $1 \% \sim 2 \%$; Using digital imaging microscope and SEM technology, the mechanism of increasing on the intensity of foamed asphalt mixture resulted by adding cement was analyzed. It revealed that the cement hydration products contained in the foamed asphalt mixture hydrolyzed into space mesh structure and wrapped up the aggregate particle, this is the main reason that the cement can enhance the mixture's intensity as well as the water stability. This research provides reference for cement admixture's formulation in the designing of foamed asphalt cold in-place recycled mixture.
\end{abstract}

\section{Introduction}

By the end of 2016, the total number of highways in china was 130,000 kilometers. So there will be a large amount of recycled asphalt mixture in the road pavement renovation, renovation and conservation every year. If calculating by $12 \%$ of highway pavement need repair, there will be 2.2 million tons recycled asphalt mixture every year ${ }^{[1]}$. Asphalt cold recycling can be a good solution, which can make the old pavement materials reused and save $40 \%-50 \%$ of the total investment ${ }^{[2]}$. Foamed asphalt is the bituminous material that contains a large amount of evenly dispersed bubbles after expansion. In a special foaming device, the expansion occurs when the heat asphalt comes into contact with the water. Now, foamed asphalt is used as a regenerative agent for recycled RAP. When foamed asphalt comes into contact with the aggregate, it suddenly becomes millions of tiny particles and spreads on the surface of the fine aggregate especially particle size less than $0.075 \mathrm{~mm}$ ${ }^{[3,4]}$. This kind of the fine aggregate with foamed asphalt can be filled in the gap between the coarse aggregate and after mixing and compacting, the asphalt rubber paste is formed that make the mixture a certain cohesion and strength. In recent years, the cold regeneration technique of recycled waste road materials by foamed asphalt has been famous for its remarkable advantages in energy saving, environmental protection and economy ${ }^{[5,6,7]}$. The

\footnotetext{
*Corresponding author: caike0501@163.com
} 
effect of foam asphalt cold regeneration is influenced by the amount of active filler such as cement. In this report, the influence factors of the stability performance of different cement foamed asphalt cold in-place recycled mixtures were studied by splitting strength test. Furthermore, using digital imaging microscope and SEM technology, we analyzed the mechanism of increasing on the intensity of foamed asphalt mixture resulted by the addition of cement.

\section{Experiment}

\subsection{Raw materials}

The recycled asphalt pavement (RAP) is from highway milling material in Wuhan, China. Through foaming experiment of Zhongtai AH-70 asphalt, the best foaming temperature is $160^{\circ} \mathrm{C}$ and water consumption is $2 \%$, and the expansion ratio is 11 times and the half-life is 10s. Stone dust is $0 \sim 3 \mathrm{~mm}$ limestone. The mine powder is limestone powder. Cement is P.O. 425 ordinary Portland cement from Huaxin cement factory, and table 1. is its chemical composition. Water is just general water.

Table 1. Chemical composition of cement.

\begin{tabular}{|c|c|c|c|c|c|c|c|c|}
\hline Chemical composition & $\mathrm{SiO}_{2}$ & $\mathrm{Al}_{2} \mathrm{O}_{3}$ & $\mathrm{Fe}_{2} \mathrm{O}_{3}$ & $\mathrm{CaO}$ & $\mathrm{MgO}$ & $\mathrm{Na}_{2} \mathrm{O}$ & $\mathrm{SO}_{3}$ & $\begin{array}{c}\text { Ignition } \\
\text { loss }\end{array}$ \\
\hline Content $/ \%$ & 21.73 & 4.25 & 2.67 & 63.59 & 2.21 & 0.55 & 2.39 & 1.75 \\
\hline
\end{tabular}

\subsection{Specimen preparation and test methods}

By comparing the particle size distribution of RAP with engineering design level gradation of foamed asphalt cold in-place recycled mixture, the mixture gradation is determined. Foamed asphalt cold in-place recycled mixtures have five different cement compositions of $0 \%, 1 \%, 1.5 \%, 2 \%, 3 \%$. The optimized amount of water used and the maximum dry density were determined by the compaction test, and the mixing water consumption is calculated. The impaction test was referring to the method in $<$ Highway Engineering stable inorganic binder materials testing procedures $>$ (JTG E 51-2009). The preparation of mixture standard Marshall specimens was refer to the methods in $<$ Road engineering asphalt and asphalt mixture test procedure $>$ (JTG 052-2000).

After demoulding, specimens kept in $40^{\circ} \mathrm{C}$ ventilation oven by $72 \mathrm{~h}$ curing. This curing method can simulate the condition after $10 \mathrm{~d}$ actual pavement construction ${ }^{[8]}$. Splitting test: Specimens at $20{ }^{\circ} \mathrm{C}$ environment after $1.5 \mathrm{~h}$ do dry splitting test; Specimens at $20{ }^{\circ} \mathrm{C}$ water flooding after $24 \mathrm{~h}$ do wet splitting test. Using digital imaging microscope and SEM technology, we analyzed the mechanism of increasing on the intensity of foamed asphalt mixture resulted by the addition of cement.

\section{Results and discussion}

\subsection{Effect of Portland cement on the foamed asphalt mixture}

Under the condition of $3 \%$ foamed asphalt, Table 2. is the splitting strength of five different cement composition specimens on different curing conditions. A is specimen curing 
condition after $24 \mathrm{~h} 20^{\circ} \mathrm{C} . \mathrm{B}, \mathrm{C}$ and D are specimen curing conditions after $24 \mathrm{~h}, 48 \mathrm{~h}$ and $72 \mathrm{~h}$ $40{ }^{\circ} \mathrm{C}$.Under the condition of $3 \%$ foam asphalt, and based on the splitting strength of specimen that is kept in $40{ }^{\circ} \mathrm{C}$ ventilation oven by $72 \mathrm{~h}$, Fig. 2 . is the percentage increase splitting strength of five different cement composition specimens on different curing conditions.

Table 2. Splitting strength of different cement composition specimens on different curing conditions.

\begin{tabular}{|c|c|c|c|c|c|c|}
\hline $\begin{array}{c}\text { Cement } \\
\text { content } \\
/ \%\end{array}$ & $\begin{array}{c}\text { A splitting } \\
\text { strength } \\
/ \mathrm{MPa}\end{array}$ & $\begin{array}{c}\mathrm{B} \text { splitting } \\
\text { strength } \\
/ \mathrm{MPa}\end{array}$ & $\begin{array}{c}\mathrm{C} \\
\text { splitting } \\
\text { strength } \\
/ \mathrm{MPa}\end{array}$ & $\begin{array}{c}\mathrm{D} \text { splitting } \\
\text { strength } \\
/ \mathrm{MPa}\end{array}$ & $\begin{array}{c}\mathrm{D} \text { wet } \\
\text { splitting } \\
\text { strength } / \mathrm{MPa}\end{array}$ & $\begin{array}{c}\text { D dry and wet } \\
\text { splitting } \\
\text { strength } \\
\text { ratio } / \%\end{array}$ \\
\hline 0 & 0.080 & 0.293 & 0.344 & 0.361 & 0.216 & 59.8 \\
\hline 1 & 0.157 & 0.350 & 0.375 & 0.412 & 0.309 & 75.1 \\
\hline 1.5 & 0.130 & 0.328 & 0.370 & 0.420 & 0.329 & 78.4 \\
\hline 2 & 0.143 & 0.333 & 0.486 & 0.512 & 0.416 & 81.2 \\
\hline 3 & 0.120 & 0.268 & 0.364 & 0.479 & 0.397 & 82.9 \\
\hline
\end{tabular}

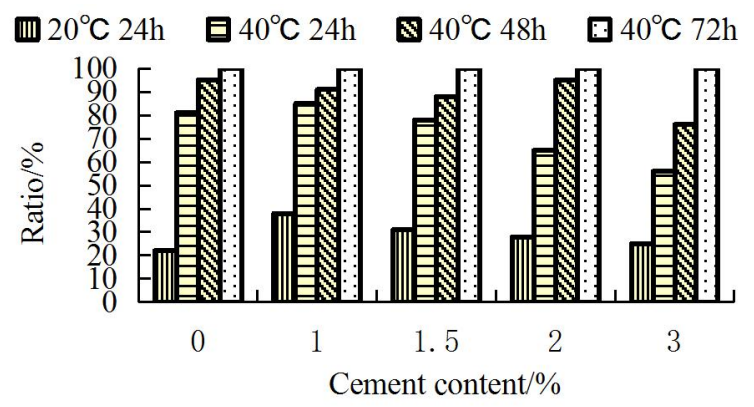

Fig.1. Increase splitting strength ratio of five different cement composition specimens on different curing conditions.

Based on the splitting strength of specimen that is kept in $40^{\circ} \mathrm{C}$ ventilation oven by $72 \mathrm{~h}$, Fig. 1. shows that after $24 \mathrm{~h}$ at room temperature curing, the increase splitting strength ratio of the mixture specimen without adding cement is $22 \%$, and the increase splitting strength ratio of the mixture specimens that adding cement is about $30 \%$. It shows that splitting strength of different cement composition mixtures is lower. After $42 \mathrm{~h}$ at $40{ }^{\circ} \mathrm{C}$ temperature curing, the increase splitting strength ratio of the mixture specimens that adding $1 \% \sim 2 \%$ cement is about $80 \%$, but the increase splitting strength ratio of the mixture specimens that adding $3 \%$ cement is only $55 \%$. It shows that early curing stage for foamed asphalt cold inplace recycled mixtures of $1 \% \sim 2 \%$ cement adding amount has rapid growth splitting strength and it is helpful to shorten the construction period of the road. Table 2 . shows that dry and ret splitting strength ratio of foamed asphalt cold in-place recycled mixtures of $1 \%$ cement adding amount is $75.1 \%$ that is more than $59.8 \%$ of none cement adding mixture. So, adding cement can obviously improve the water stability of foam asphalt mixture. When cement adding amount is 3\%, dry and ret splitting strength ratio is $82.9 \%$ that is not much higher than $1 \%$ cement adding mixture. Based on engineering economy and dry and ret splitting strength ratio not less than $75 \%$ which is the rule for the regeneration of road asphalt pavement, the best cement admixture of this foamed asphalt cold recycled mixture is between $1 \% \sim 2 \%$. 


\subsection{Mechanism}

Fig. 2(a). is the digital imaging microscope images for $1 \%$ cement adding amount Marshall specimen surface. Fig. 2(b). is the digital imaging microscope images for $2 \%$ cement adding amount Marshall specimen surface. The figure shows that $1 \%$ cement adding amount Marshall specimens surface accumulation and crowding are compact and porosity is lower than $0 \%$ cement adding amount one. The greater porosity, the permeability is increasing. The moisture content is easy to infiltrate the interface of asphalt and the aggregate, and exchange caking property causing water damage. As a result, the stability of the mixture is reduced.

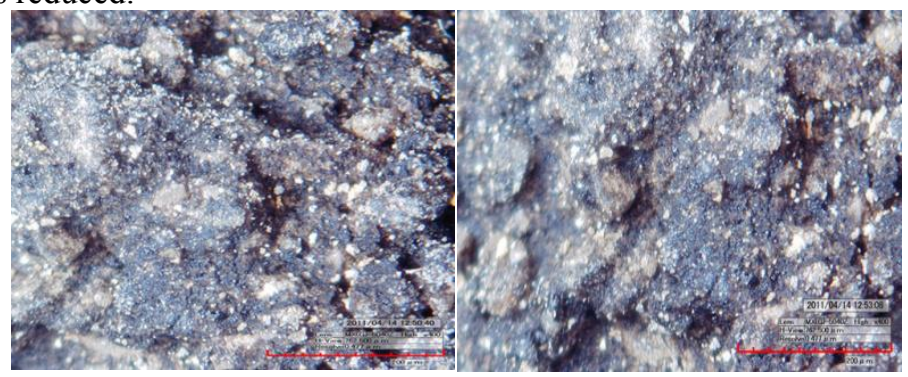

(a) $1 \%$ cement adding amount

(b) $2 \%$ cement adding amount

Fig.2. Digital imaging microscope images of the mixture

After the hydration of the cement in cold cycling mixture, some of the hydration products $\mathrm{C}_{4} \mathrm{AH}_{13}$ react with gypsum: $\mathrm{C}_{4} \mathrm{AH}_{13}+3 \mathrm{C} \overline{\mathrm{S}} \mathrm{H}_{2}+14 \mathrm{H}=\mathrm{AFt}+\mathrm{CH}$. The needle bar AFt will be filled space within the mix and form a network structure that increased mixture strength. Others hydration products C-S-H coagulation forms a fibrous structure that further increased mixture strength ${ }^{[9]}$. Hydration products develop to the surrounding space of the cement particles, criss-cross, and gradually fill the mix of all the capillary space. Thereby it forms a uniform, dense, pore closed the whole structure, and enhances the overall strength of the mixture of water and anti-damaging ${ }^{[10]}$. It is clear that acicular and fibrous gels are interwoven overlapping to form a network structure in Fig. 3. Thus, the cement hydration products contained in the foamed asphalt mixture hydrolyzed into space mesh structure and wrapped up the aggregate particle. It is the main reason that the cement can enhance the mixture's intensity as well as the water stability. The amount of cement is not the higher the better. The mixture of high cement adding is easy to produce severe shrinkage cracks and it leads to lower strength. This research provides reference for cement admixture's formulation in the designing of foamed asphalt cold in-place recycled mixture.

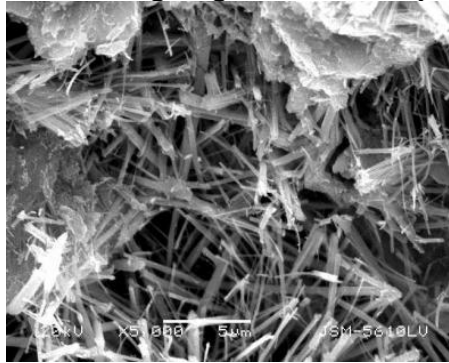

(a) Acicular gels

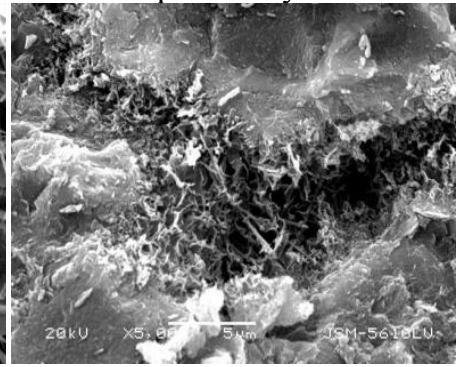

(b) Fibrous gels

Fig.3. SEM images for hydration products of the mixture 


\section{Conclusions}

Addition of cement can obviously improve foamed asphalt mixture's water stability and the best cement admixture of this foamed asphalt cold recycled mixture is between $1 \% \sim 2 \%$. Early curing stage for mixtures of 1\% 2\% cement adding amount has rapid growth splitting strength and it is helpful to shorten the construction period of the road. The cement hydration products contained in the foamed asphalt mixture hydrolyzed into space mesh structure and wrapped up the aggregate particle. It is the main reason that the cement can enhance the mixture's intensity as well as the water stability. But the amount of cement should be controlled in the appropriate range. This research provides reference for cement admixture's formulation in the designing of foamed asphalt cold in-place recycled mixture.

This work was financially supported by National Key Research and Development Program (2016YFC1400802) and Provincial key Research and Development Program (2016GGH4501).

\section{References}

1. G.K. Wang, Z.L.Zhou. Foamed Asphalt Cold in-plant Recycling Applied in Pavement, Reconstruction Transport Standardization, 219 (2010), pp.112-117

2. Guidelines for Cold In-Place Recycling[M]. Asphalt Recycling and Reclaiming Association, Annapolis, MD, 1991.

3. L.Y. Wei, Z.W. Liu, H.R. Zhang, J. Wang. Experimental Analyse of Foamed Asphalt Stabilization Cold-recycled Mixture in Old Asphalt Pavement, Journal of Hebei University of Technology. 37(2008), p.100-104

4. C.X. Cao, G.P. He, C.R. Sun. The Cold Regeneration Technique by foamed asphalt, Highway, 11 (2003), p.99-101

5. Z.K. Xu. Effect of Foam Asphalt and Cement Content on Road Performance of Cold Recycled Asphalt Mixture, Highway Engineering, 42 (2017), p. 245

6. T.Q. Ling, L. He, Y. Ma. A Cold Recycling Technique for Foamed Bitumen Mix, Journal of Civil Architectural\&Environmental Engineering, 31 (2009), pp.141-145

7. F. Z. Shi, X.J. Li, D.Q. Sun, W.M. Lv. Discussion about Design Methods for Recycling Cold Mix Asphalt [J].Highway, 11 (2004), p.103-107.

8. X.J. Li. Guide Experimental Study on Shearing Properties of Cold-Recycled Mixtures Using Foamed Asphalt, Journal of Building Materials,13(2010), p.27

9. Y.Z. Yuan. Gelling Material Science, Wuhan University of Technology Press, 2008.p.93-101

10. X. B. Yin. Performance of Emulsified Asphalt Full Thickness Cold Recycling Subgrade Materials, Advanced Materials Research, 915-916 (2014), p. 704 